\title{
Association of CD58 polymorphism and multiple sclerosis in Malaysia: a pilot study
}

Yee Ming Ching ${ }^{1}$, Shanthi Viswanathan², Nurhanani Mohamed Nor', Shuwahida Shuib', Balqis Kamarudin', Salawati Mansor ${ }^{1}$, Ainur Yusniza Yusof ${ }^{1}$ and Masita Arip ${ }^{1,3^{*}}$

\begin{abstract}
Background: Multiple sclerosis is an immune mediated disease targeting the central nervous system. Association of non-human leukocyte antigen gene, CD58, with multiple sclerosis has been reported in several populations but is unclear among Southeast Asians. This pilot study was conducted to explore the association between CD58 polymorphism and multiple sclerosis among the Malay population in Malaysia.

Methods: Blood samples were collected from 27 multiple sclerosis patients, and compared with 58 age- and gender matched healthy individuals. All patients were tested negative for anti-aquaporin 4. DNA was extracted from the blood and genotyped for 3 single nucleotide polymorphisms rs12044852, rs2300747 and rs1335532 of gene CD58 by real-time PCR.

Results: The majority of multiple sclerosis patients were female (85.2\%). The general mean age of onset was 30.5 years. Genotyping results showed that frequencies of the alleles were between 40 and $50 \%$ for MS patients and healthy individuals. Association (allelic model) between multiple sclerosis and CD58 gene polymorphism alleles rs $12044852(p=0.410)$, rs $2300747(p=0.881)$ and rs $1335532(p=0.407)$ were indistinct.

Conclusions: The impact of the CD58 gene polymorphism was not prominent in this pilot study, implying that genetic composition contributing to multiple sclerosis may be different between different populations, thus results in a heterogeneity of disease manifestation and distribution.
\end{abstract}

Keywords: Multiple sclerosis, CD58 polymorphism, Single nucleotide polymorphism

\section{Background}

Multiple Sclerosis (MS) is an immune-mediated disease characterized by inflammation and demyelination of the central nervous system (CNS). MS patients can present with a broad spectrum of neurological symptoms such as visual loss, muscle weakness, sensory loss, incoordination, cognitive dysfunction and bladder problems [1]. A systemic analysis of MS has reported that age-standardized prevalence was greater than 120 cases per 100,000

\footnotetext{
*Correspondence: masita@imr.gov.my

${ }^{3}$ Allergy and Immunology Research Centre, Institute for Medical Research, Block C6, National Institute of Health Complex, No. 1, Jalan Setia Murni U13/52, Seksyen U13, Bandar Setia Alam, 40170 Shah Alam, Selangor Darul Ehsan, Malaysia

Full list of author information is available at the end of the article
}

population in North America and some northern European countries, moderate $(60-120$ per 100,000$)$ in some countries in Europe and Australasia, and lower in Africa, Asia and northern South America region (5 per 100 000) $[2,3]$. In Malaysia, the prevalence of MS was estimated to range from 2 to 3 per 100,000 [4, 5].

The development of MS is commonly associated with the interaction between genetic susceptibility and environmental factors. Genetic association of MS, especially the variation in human leukocyte antigen (HLA) location on chromosome 6 , has been generally considered as the highest risk for the disease development [6]. However, the influence of the $H L A$ gene alone is insufficient to fully explain the role of genetic in the pathogenesis of the disease. A genome wide association study of MS

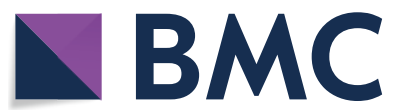

(c) The Author(s) 2019. This article is licensed under a Creative Commons Attribution 4.0 International License, which permits use, sharing, adaptation, distribution and reproduction in any medium or format, as long as you give appropriate credit to the original author(s) and the source, provide a link to the Creative Commons licence, and indicate if changes were made. The images or other third party material in this article are included in the article's Creative Commons licence, unless indicated otherwise in a credit line to the material. If material is not included in the article's Creative Commons licence and your intended use is not permitted by statutory regulation or exceeds the permitted use, you will need to obtain permission directly from the copyright holder. To view a copy of this licence, visit http://creativeco mmons.org/licenses/by/4.0/. 
patients among the United States (US) and United Kingdom (UK) was performed by the International Multiple Sclerosis Genetics Consortium (IMSGC) in 2007. They found that several single nucleotide polymorphisms (SNPs) from the non-HLA region were highly associated with MS [7]. One of the MS related non-HLA genes is $C D 58$.

The CD58 gene is located on chromosome one and it encodes a member of the $\mathrm{T}$ lymphocytes $\mathrm{CD} 2$ protein ligand, which plays an important role in signal transduction in $\mathrm{T}$ cell activation [8, 9]. Regulation of $\mathrm{T}$ cells is crucial in maintaining the body's immune response and tolerance towards self and foreign antigens. Failure of immune tolerance towards self-antigens results in autoimmunity. The CD58 SNPs have been studied in European ancestry $[10,11]$ but little is known about their association with MS in Asian, especially in Southeast Asian. Therefore, in this study, we aimed to explore and investigate the association of several CD58 SNPs and MS in the Malay population in Malaysia.

\section{Methods}

\section{Subjects of study}

Samples for this study consisted of 27 MS patients, who were recruited from the Neurology Clinic, of Hospital Kuala Lumpur. This study enrolled patients of Malay ancestry and were diagnosed with Multiple Sclerosis (MS) by a neurologist based on the revised McDonald criteria of 2017 [12]. Clinical subtypes of the disease included relapsing-remitting MS (RRMS) and secondary progressive MS (SPMS). Demographic data and characteristic of patients such as duration of disease, age onset, MRI results (infratentorial lesion and juxtacortical lesion) and Expanded Disability Status Scale (EDSS) scores were collected. All samples were tested for anti-aquaporin 4 antibodies using commercially available kit (Euroimmun, Lubeck, Germany). Patients with positive anti-aquaporin 4 antibodies were excluded from the study. The control group comprised 58 biological unrelated individuals of the same ethnic background and similar age. Informed consent was obtained from all patients and control individuals participating in this study and their anonymity was preserved. This study was approved by the Medical Research and Ethics Committee of Malaysia Ministry of Health (NMRR-13-1029-18067).

\section{Sample preparation and genotyping}

DNA was extracted from blood samples according to the standard method using the commercial DNA extraction kit (Qiagen, Germany). Three SNPs (rs12044852, rs1335532 and rs2300747) in CD58 gene were selected based on findings of genome wide association studies (GWAS) and were reported to be highly associated with MS [7, 11, 13]. The 3 SNPs were genotyped for all study subjects and control using Taqman assay (Applied Biosystems, USA): Taqman SNP Genotyping assay C_31433800_10 (rs12044852), C_15755405_10 (rs2300747) and C_8700717_10 (rs1335532), on the ABI 7500 Fast Real-time PCR system (Thermo Fisher Scientific, USA).

\section{Statistical analysis}

Statistical analysis was performed using IBM SPSS Statistics version 22 for Windows (IBM Corp, USA). Allele frequencies for MS patients and healthy controls were calculated and compared to healthy controls. The association between CD58 polymorphism and MS patients' characteristics was analysed using Chi square or twotailed Fisher's exact test, odd ratios (OR) and 95\% confidence interval $(95 \% \mathrm{CI})$ were calculated. Value of $\mathrm{p} \leq 0.05$ was considered statistically significant.

\section{Results}

Our study population consisted of 27 Malay MS patients, predominantly female, with female to male ratio of 5.8:1. Control groups comprised 52 females and 6 males of healthy individuals. The demographic and clinical features of the study population are shown in Table 1. Majority of MS patients in this study population were diagnosed as RRMS (81.5\%).

Allelic prevalence for each of the CD58 SNPs studied shows a range of 40 to $50 \%$ for each allele in both MS

Table 1 Demographic and clinical features of study subjects

\begin{tabular}{lrr}
\hline Variables & Controls, N (\%) & MS patients, N (\%) \\
\hline Female & $52(89.7)$ & $23(85.2)$ \\
Male & $6(10.3)$ & $4(14.8)$ \\
$\quad$ Age of onset, mean \pm SD (range) & & $30.5 \pm 10.3(16-56)$ \\
Age of time of analysis, mean \pm SD (range) & $42.3(26-65)$ & $36.5 \pm 11.7(20-62)$ \\
Disease type & & $22(81.5)$ \\
$\quad$ Relapsing remitting MS (RRMS) & & $5(18.5)$ \\
Secondary progressive MS (SPMS) & & \\
\hline
\end{tabular}


patients and controls (Table 2). Frequencies of CD58 haplotypes for this study population are shown in Table 3. Table 4 shows the association analysis of the CD58 SNP alleles $r s 12044852(\mathrm{p}=0.410), \operatorname{rs} 1335532(\mathrm{p}=0.881)$ and rs2300747 $(\mathrm{p}=0.407)$ between MS patients and controls. Analysis of the results revealed no significant association between CD58 SNPs and age of onset, MRI parameters and disease activity. CD58 SNPs were also not significantly different between types of MS.

Table 2 Genotype distribution and allele frequency CD58 SNPs in MS patients and controls

\begin{tabular}{|c|c|c|c|}
\hline SNPs & $\begin{array}{l}\text { Genotypes/ } \\
\text { Alleles }\end{array}$ & MS (\%) & Controls (\%) \\
\hline \multirow[t]{5}{*}{ Rs12044852 } & AA & 18.5 & 31.0 \\
\hline & $A C$ & 55.6 & 46.6 \\
\hline & $\mathrm{CC}$ & 25.9 & 22.4 \\
\hline & A & 46.3 & 54.3 \\
\hline & $C$ & 53.7 & 45.7 \\
\hline \multirow[t]{5}{*}{ Rs1335532 } & GG & 25.9 & 39.7 \\
\hline & GA & 63.0 & 37.9 \\
\hline & AA & 11.1 & 22.4 \\
\hline & G & 57.4 & 58.6 \\
\hline & A & 42.6 & 41.4 \\
\hline \multirow{5}{*}{ Rs2300747 } & AA & 18.5 & 20.7 \\
\hline & $A G$ & 59.3 & 41.4 \\
\hline & GG & 22.2 & 37.9 \\
\hline & A & 48.1 & 41.4 \\
\hline & G & 51.9 & 58.6 \\
\hline
\end{tabular}

Table 3 Frequency of CD58 haplotypes in this study

\begin{tabular}{lllll}
\hline Haplotype (Ht) & Rs1335532 & Rs2300747 & Rs12044852 & Frequency \\
\hline Ht1 & G & G & A & 0.511 \\
Ht2 & A & A & C & 0.405 \\
Ht3 & G & G & C & 0.047 \\
Ht4 & G & A & C & 0.024 \\
Others & & & & 0.013 \\
\hline
\end{tabular}

Table 4 Allelic analysis of CD58 SNPs in MS patients and control

\begin{tabular}{lllll}
\hline SNPs & Alleles & p value & OR & $\mathbf{9 5 \% ~ C l}$ \\
\hline RS12044852 & A,C & 0.410 & 0.7 & $0.4-1.4$ \\
RS1335532 & G,A & 0.881 & 1.1 & $0.5-2.0$ \\
RS2300747 & A,G & 0.407 & 1.3 & $0.7-2.5$ \\
\hline
\end{tabular}

\section{Discussion}

Single nucleotide polymorphisms (SNPs) are the most common type of DNA polymorphisms in human and their relations with autoimmune diseases such as MS are noteworthy. Association of SNPs in non-HLA genes and autoimmune diseases has been reported in various studies involving the US and European population in the last decades $[14,15]$.

For MS, one of the candidate non-HLA genes reported to be associated with the disease is CD58 [16]. It is suggested that alteration of $C D 58$ expression affects the regulation of FoxP3, a protein highly expressed in regulatory $\mathrm{T}$ cells (Treg), leading to functional changes in Treg cells and influence the body's immune response against its own cells. Dysfunction or reduction of Treg has been reported in various studies of autoimmune diseases including MS [17]. The expression of CD58 mRNA has been shown to be increased significantly in samples collected from MS patients during remission than those sampled during relapse [13].

The demographic characteristic of this study is in agreement with findings of other studies. Age of onset in this study population ranged from 16 to 56 years old, with mean of $30.5 \pm 10.3$ years which falls within the range of findings in other studies around the region: $28.6 \pm 9.9$ years in another study in Malaysia [18] and $32.7 \pm 11.5$ years in Thailand [19]. In South India, the age of onset was noted at $38.3 \pm 12.8$ years [20]. Out of 27 MS patients in this study, about $85.2 \%$ were females and $14.8 \%$ were males, with female to male ratio of 5.8:1. The ratio is consistent with an analysis of data from the Danish Multiple Sclerosis Registry that showed the incidence in women doubled between 1950 and 2009, while the increases among men were relatively moderate [21]. The rapid change in incidence among women might be due to environmental changes such as the rise in obesity, increased cigarette smoking, and changes in the frequency of breastfeeding infants $[21,22]$.

In this pilot study, we investigated the possible association of CD58 SNPs, namely rs2300747, rs12044852 and rs1335532, with MS amongst Malay population in Malaysia. Our results showed that the frequency of rs2300747G was higher in the control group compared to the MS patients, suggesting a potential of a protective value in rs2300747G, although the difference was statistically insignificant. A study done by De Jager et al. indicated that rs2300747G was a protective allele associated with MS and that East Asian cell lines expressed higher frequencies of rs2300747G compared to the cell lines of Europe ancestry, which might explain a lower 
frequency of MS amongst Asians [11]. This is also supported by a meta-analysis done by Liu et al. [23] which reported polymorphism of rs $2300747 \mathrm{G}$ as a protective allele against MS. However, findings of SNP rs2300747 and MS were inconsistent in different populations. Like our results, no evidence of protective allele in SNP rs2300747 was found in a study on the association of non-MHC region and MS among Indian population in India [24].

In a replication GWAS study conducted by The Australia and New Zealand Multiple Sclerosis Genetics Consortium (ANZgene) which analysed more than 1500 MS cases, it was reported that SNP rs1335532 of CD58 is one of the non-HLA SNPs that was highly associated with MS [13]. However, the same SNP has been reported to be significantly associated with neuromyelitis optica spectrum disorders (NMOSD), another spectrum of inflammatory demyelinating disease, in a case-control study of Koreans $[25,26]$. On the other hand, the other CD58 SNPs, rs12044852, has been repeatedly reported to be associated with MS [27, 28]. A case-control study involving 200 MS patients and 200 healthy controls in a subset of Iranian population reported that the rs12044852 polymorphism of CD58 has a profound effect on the onset of MS but not significantly associated with patients' gender, disease severity and type of MS [29]. Our results showed that the rs12044852 polymorphism was not significantly associated with MS. This is also similar to a study focused on genetic susceptibility to MS in African Americans, that showed rs12044852 and rs2300747 were not significantly associated with MS [30].

There were a number of limitations in our study which possibly restricted the analysis of the results and affected the outcome of the study. Compared with other studies on SNPs [13, 31], the number of patients and controls recruited in this study was relatively small for genetic association study and may not represent the true population. Small sample size also has less statistical power and could introduce bias to this study, leading to insignificant results. Although a larger sample size could increase statistical power, it could also be costly and takes longer time frame to complete the sample collection due to the relatively low frequency of autoimmune diseases around the region. Another option that can be considered to improve this study is by increasing the sample size of the control to 1:4 case-control ratio if the assumptions of model can be fulfilled [32]. Another limitation in this study that can be improved is the location of sample collection. Due to location of the hospital, patients recruited in this study were mainly from the central urban region of Peninsular Malaysia. This could introduce bias as the Malay population in Malaysia can be clustered into a few sub-ethnic groups that could be genetically different [33]. In addition to that, like other autoimmune diseases, the development of MS involves a complex interaction between genetic susceptibility and environmental factors. CD58 gene may play an indirect role in disease development and the differences in other genetic components of our study population may have contributed to the outcome.

In conclusion, our exploratory study did not show significant association between CD58 SNPs (rs12044852, rs1335532 and rs2300747) and MS in our study population. However, further investigations with optimal sample size, more genetic markers and correlation with environmental factors are necessary to help shed some light on this disease in our country.

\section{Abbreviations}

MS: Multiple sclerosis; HLA: human leukocyte antigen; SNPs: single nucleotide polymorphisms; RRMS: relapsing-remitting MS; SPMS: secondary progressive MS; EDSS: Expanded Disability Status Scale.

\section{Acknowledgements}

The authors would like to thank the Director General of Health Malaysia for his permission to publish this article.

\section{Authors' contributions}

CYM, SV, SM, AYY and MA designed and conceptualized the study; CYM, SV, NMN, SS, BK and SM acquired and analyzed data; all authors were involved in interpretation of data; all authors were involved in drafting, revising the manuscript and approving the manuscript; CYM was a major contributor in writing the manuscript. All authors read and approved the final manuscript.

\section{Funding}

This study was funded by National Institute of Health Malaysia (NMRR-13-1029-18067).

\section{Availability of data and materials}

The datasets used and/or analysed during the current study are available from the corresponding author on reasonable request.

\section{Ethics approval and consent to participate}

Informed consent was obtained from all participants. Identification details were removed to maintain the anonymity. This study was approved by Medical Research and Ethics Committee of Malaysia Ministry of Health (NMRR-13-1029-18067).

\section{Consent for publication}

Not applicable.

\section{Competing interest}

The authors declare that they have no competing interest.

\section{Author details}

${ }^{1}$ Autoimmune Unit, Allergy and Immunology Research Centre, Institute for Medical Research, National Institute of Health, Selangor, Malaysia. ${ }^{2}$ Neurology Department, Hospital Kuala Lumpur, Kuala Lumpur, Malaysia. ${ }^{3}$ Allergy and Immunology Research Centre, Institute for Medical Research, Block C6, National Institute of Health Complex, No. 1, Jalan Setia Murni U13/52, Seksyen U13, Bandar Setia Alam, 40170 Shah Alam, Selangor Darul Ehsan, Malaysia.

Received: 5 September 2019 Accepted: 6 December 2019

Published online: 17 December 2019 


\section{References}

1. Loma I, Heyman R. Multiple sclerosis: pathogenesis and treatment. Curr Neuropharmacol. 2011;9:409-16.

2. Chong HT. Multiple sclerosis in South East Asia and diagnostic criteria for Asians. Neurol Asia. 2008;13:145-6.

3. GBD 2016 Neurology Collaborators. Global, regional, and national burden of neurological disorders, 1990-2016: a systematic analysis for the global burden of disease study 2016. Lancet Neurol. 2019;18(5):459-80.

4. Chong HT, Tan CT. A review of multiple sclerosis with Asian perspective. Med J Malaysia. 2008;63:356-61.

5. Tan C-T. Multiple sclerosis in Malaysia. Arch Neurol. 1988;45:624-7.

6. International multiple sclerosis genetics consortium. A high-density screen for linkage in multiple sclerosis. Am J Hum Genet. 2005;77:454-67.

7. International multiple sclerosis genetics consortium. Risk alleles for multiple sclerosis identified by a genomewide study. N Engl J Med. 2007:357:851-62

8. Davis SJ, van der Merwe PA. The structure and ligand interactions of CD2: implications for T-cell function. Immunol Today. 1996;17:177-87.

9. Mestas J, Hughes CCW. Endothelial cell costimulation of T cell activation through CD58-CD2 interactions involves lipid raft aggregation. J Immunol. 2001;167:4378-85.

10. Hoppenbrouwers IA, Aulchenko YS, Janssens AC, Ramagopalan SV, Broer $L$, Kayser M, et al. Replication of CD58 and CLEC16A as genome-wide significant risk genes for multiple sclerosis. J Hum Genet. 2009;54:676-80.

11. De Jager PL, Baecher-Allan C, Maier LM, Arthur AT, Ottoboni L, Barcellos $\mathrm{L}$, et al. The role of the CD58 locus in multiple sclerosis. PNAS. 2009:106:5264-9.

12. Thompson AJ, Banwell BL, Barkhof F, Carroll WM, Coetzee T, Comi G, et al. Diagnosis of multiple sclerosis: 2017 revisions of the McDonald criteria. Lancet Neurol. 2018;17:162-73.

13. Bahlo M, Booth DR, Broadley SA, Brown MA, Foote SJ, Griffiths LR, et al. Genome-wide association study identifies new multiple sclerosis susceptibility loci on chromosomes 12 and 20. Nat Genet. 2009:41:824-8.

14. Sharma A, Liu X, Hadley D, Hagopian W, Liu E, Chen W-M, et al. Identification of non-HLA genes associated with celiac disease and countryspecific differences in a large, international pediatric cohort. PLOS ONE. 2016;11:e0152476.

15. Steck AK, Bugawan TL, Valdes AM, Emery LM, Blair A, Norris JM, et al. Association of Non-HLA genes with Type 1 diabetes autoimmunity. Diabetes. 2005:54:2482-6.

16. Bahreini SA, Jabalameli MR, Saadatnia M, Zahednasab $H$. The role of nonHLA single nucleotide polymorphisms in multiple sclerosis susceptibility. J Neuroimmunol. 2010;229:5-15.

17. Viglietta V. Loss of functional suppression by CD4 + CD25 + regulatory T cells in patients with multiple sclerosis. J Exp Med. 2004;199:971-9.

18. Viswanathan S, Rose N, Masita A, Dhaliwal JS, Puvanarajah SD, Rafia $\mathrm{MH}$, et al. Multiple sclerosis in Malaysia: demographics, clinical features, and neuroimaging characteristics. Mult Scler Int. 2013. https://doi. org/10.1155/2013/614716.
19. Siritho S, Prayoonwiwat N, Pulkes T, Chankrachang S, Laptikultham S, Nidhinandana S, et al. A retrospective study of multiple sclerosis in Thailand. Neurol Asia. 2010;15(3):253-61.

20. Pandit L, Kundapur R. Prevalence and patterns of demyelinating central nervous system disorders in urban Mangalore, South India. Mult Scler. 2014;20:1651-3.

21. Koch-Henriksen N, Thygesen LC, Stenager E, Laursen B, Magyari M. Incidence of MS has increased markedly over six decades in Denmark particularly with late onset and in women. Neurol. 2018;90:e1954-63.

22. Langer-Gould A, Smith JB, Hellwig K, Gonzales E, Haraszti S, Koebnick C, et al. Breastfeeding, ovulatory years, and risk of multiple sclerosis. Neurol. 2017:89:563-9.

23. Liu J, Liu X, Liu Y, Deng S, Huang H, Chen Q, et al. Association of EVI5 rs11808092, CD58 rs2300747, and CIITA rs3087456 polymorphisms with multiple sclerosis risk: a meta-analysis. Meta Gene. 2016;9:97-103.

24. Pandit L, Ban M, Sawcer S, Singhal B, Nair S, Radhakrishnan K, et al. Evaluation of the established non-MHC multiple sclerosis loci in an Indian population. Mult Scler J. 2011;17:139-43.

25. Kim JY, Bae JS, Kim HJ, Shin HD. CD58 polymorphisms associated with the risk of neuromyelitis optica in a Korean population. BMC Neurol. 2014;14:57.

26. Wingerchuk DM, Banwell B, Bennett JL, Cabre P, Carroll W, Chitnis T, et al. International consensus diagnostic criteria for neuromyelitis optica spectrum disorders. Neurol. 2015;85:177-89.

27. Hecker M, Blaschke J, Blaschke P, Fitzner B, Koczan D, Thiesen H-J, et al. CD58 and multiple sclerosis: genetic association, gene expression and prognostic value (P6.156). Neurology. 2014;82:P6.156.

28. Brynedal B, Lima Bomfim I, Olsson T, Duvefelt K, Hillert J. Differential expression, and genetic association, of CD58 in Swedish multiple sclerosis patients. PNAS. 2009;106:23.

29. Torbati S, Karami F, Ghaffarpour M, Zamani M. Association of CD58 polymorphism with multiple sclerosis and response to interferon $ß$ therapy in a subset of Iranian population. Cell J. 2015;16(4):506-13.

30. Johnson BA, Wang J, Taylor EM, Caillier SJ, Herbert J, Khan OA, et al. Multiple sclerosis susceptibility alleles in African Americans. Genes Immun. 2010;11:343-50.

31. Baranzini SE, Wang J, Gibson RA, Galwey N, Naegelin Y, Barkhof F, et al. Genome-wide association analysis of susceptibility and clinical phenotype in multiple sclerosis. Hum Mol Genet. 2009;18:767-78.

32. Hong EP, Park JW. Sample size and statistical power calculation in genetic association studies. Genomics Inform. 2012;10:117.

33. Hatin WI, Nur-Shafawati AR, Zahri M-K, Xu S, Jin L, Tan S-G, et al. Population genetic structure of Peninsular Malaysia malay sub-ethnic groups. PLOS ONE. 2011:6:e18312.

\section{Publisher's Note}

Springer Nature remains neutral with regard to jurisdictional claims in published maps and institutional affiliations.
Ready to submit your research? Choose BMC and benefit from:

- fast, convenient online submission

- thorough peer review by experienced researchers in your field

- rapid publication on acceptance

- support for research data, including large and complex data types

- gold Open Access which fosters wider collaboration and increased citations

- maximum visibility for your research: over 100M website views per year

At BMC, research is always in progress.

Learn more biomedcentral.com/submissions 